\title{
Influence of Peer Pressure on Junior Secondary School Students' Academic Performance in Social Studies in Mushin Local Government Area, Lagos State
}

\author{
Babatunde Adeniyi Adeyemii. Ph.D* \\ Institute of education Obafemi Awolowo University, ile-ife Osun State Nigeria
}

\section{${ }^{*}$ Corresponding Author}

Babatunde Adeniyi Adeyemii

\section{Article History}

Received: 20.09.2019

Accepted: 06.10.2019

Published: 02.10.2019

\begin{abstract}
The study assessed the level of peer pressure among junior secondary school students of Social Studies in Mushin Local Government Area, Lagos State. It also determined the difference between male and female junior secondary school students of Social Studies peer pressure influence on their academic performance and examined the difference across age groups peer pressure influence on academic performance of junior secondary school students in Social Studies in the study area. The study adopted a descriptive survey research design. The target population is the junior secondary school students in Mushin Local Government Areas of Lagos state, Nigeria. Eight junior secondary schools were selected using simple random sampling technique. From each of the schools, thirty students were selected using simple random sampling technique summing up to 240 students that made up the sample for the study. Two self-designed research instruments were used for the study namely: Peer Pressure Questionnaire (PPQ) and Social Studies Test (SST). Data collected were analyzed using frequency, simple percentage, graph and multivariate analysis of variance (MANOVA). The results of the study showed that the students demonstrated moderate peer pressure influence in junior secondary schools, 148(61.7\%). The results of the study further indicated that there was no statistically significant difference between male and females on the combined dependent variables $\left(F_{(2,237)}=0.97, p>0.05\right)$. The results of the findings finally revealed that there was no statistically significant difference between different age groups on the combined dependent variables in the study area $\left(F_{(2,236)}=0.65\right.$, $p>0.05$ ). The study therefore concluded that the level of peer pressure among junior secondary school students is moderate and that the peer pressure influenced their academic performance though moderating variables have no significant influence on the students' performance in Social Studies in the study area.
\end{abstract}

Keywords: Peer Pressure, Academic Performance, Social Studies.

\section{INTRODUCTION}

Educational activities are geared towards ensuring that students achieve the mastery of educational objectives. It is observed in school that the extent to which these objectives have been achieved, is determined by their level of peer pressure, time management as students' success are reflected in their academic performance. Peers play a large role in the social and emotional development of an adolescent [1]. Their influence begins at an early tender age and increases through the teenage years, it is natural, healthy and important for adolescent to have and rely on friends as they grow and mature. Thus, a peer could be any one you look up to in behaviour or someone who you would think is equal to your age or ability [2]. The term "pressure" implies the process that influence people to do something that they might not otherwise choose to do or not willing to do.

Adolescence in children is a time of transformation in many areas of an individual's life. In the midst of these rapid physical, emotional, and social changes, children begin to question adult standards and the need for parental guidance. It is also a time for individuals to make crucial decisions about their commitment to academics and family. As adolescents make the transition to their primary schools to junior secondary schools or perhaps high school, peer networks increase, and peer crowd affiliation becomes an important aspect of peer relations [3]. At the junior secondary classes, dating relationships emerge and take on increasing importance. By age ten (10) to sixteen (16), majority of adolescents report having had a romantic relationship [4]. Thus, adolescence is characterized by changes in terms of physical, thinking, and problem - solving as well as emotional and sexual maturation [5].

Copyright @ 2019: This is an open-access article distributed under the terms of the Creative Commons Attribution license which permits unrestricted use, distribution, and reproduction in any medium for non commercial use (NonCommercial, or CC-BY-NC) provided the original author and source are credited. 
In addition, adolescents have always been exposed to peer influence, but the kinds of peer influence that they encounter have changed tremendously in the recent years. Peers can influence everything from what an adolescent chooses to wear, drink or eat to whether or not an adolescent engages in drug - related or other delinquent behavior [6]. This is an important issue to be studied because if society and education related professionals understand the issue surrounding negative peer influence, they can adequately prepare themselves to help teenagers facing negative aspects of peer pressure. According to Jones [7], defined peer pressure as the ability of people from the same social rank or age to influence another of same age bracket; peer pressure is usually associated with teens although its influence is not confined to teenagers alone. Hartney [8] peer pressure refers to the influences that peers can have on each other. Weinfied [9] Peer pressure is emotional or mental forces from people belonging to the same social group (such as age, grade or status) to act or behave in a manner similar to themselves.

However, peers can also have a negative influence on one another such as encouraging each other to skip classes, steal, cheat, bully, use of drugs or alcohol, or become involve in other risky behaviours within or outside the learning palace. Negative peer pressure may influence in various ways like joining group who drink alcohol, smoke cigarette and Indian hemp among others. It may also lead to the decision to dating relationship such as having boyfriend or girlfriend. Peer pressure indulges youth into loitering about in the streets, watching films, going to pools and attending parties during school hours, taping as alternative to stealing which may eventually graduate into a big criminal act [10]. Peer pressure may be present in the workplace, at school or within the society. It can affect people of all ages and it may affect people in different ways but the main focus of this project is on peer pressure as it influences academic performance of in school adolescents in junior secondary school.

Academic performance on the other hand refers to how well a student is accomplishing his or her tasks and studies [11]. Grades are certainly the most well - known indicator of academic performance. Grades basically are student's "scores" for their classes and overall tenure. Grades are most often a tallying or average of assignment, test scores, examination and may often be affected by factors such as attendance an instructor opinion of the student as well. Grading systems vary greatly by country and school; common scales include a percentage form 1 - 100, lettering systems from A - F, and grade point averages (GPA) from 0 5.0. According to Ward, Stocker and Murray-Ward [12] academic performance refers to the outcome of education; the extent to which the student, teacher or school have achieved their educational goals. Academic performance is the ability to study and remember facts and being able to communicate one's knowledge orally or written on paper. Therefore, academic achievement or performance refers to the extent to which students have achieved mastery of the objectives of the subjects they are exposed to in school. According to Aremu \& Sokan [13], academic achievement has been observed in school subjects especially Mathematic, English language, Basic Science and Technology, Religious and National Value Education among junior secondary school students.

The blame for poor academic performance among junior secondary school students could be attributable to a variety of factors such as student inability to manage their time, peers influence, family factors and the likes. Parents, teachers, curriculum experts and evaluators have expressed considerable concern over the deteriorating students' performance in public examinations such as Basic Education Certificate Examination (BECE) and National Examination Council (NECO). Therefore, students within adolescent age should avoid negative pressure such loitering along the street during school hours, holding parties at the expense of their study claiming to be celebrating a birthday, skipping school and drug abuse. That will create room for poor academic performance. The adolescent should move with people that study their books in order to have good academic performance.

\section{Statement of the Problem}

The stakeholders in education are expressing considerable concern about the poor performance of students in external examination such as Basic Education Certificate Examination and other National Examinations. These groups of individuals tend to place a larger percentage of the blame on influence of negative peer pressure and poor time management by the students (i.e. as they devote more attention to social media than they do to their study) as being responsible for poor academic performance. These factors are suspected for the luring of adolescents into engagement in negative habits such as of late coming to schools, moving round the streets, absents from schools among students is very disturbing which appear to make students to miss some topics taught in schools, engagement in unhealthy sexual behavior, cultist activities and other behaviors that distract them from their academic pursuit. It is in view of this that the study sets out to determine the influence of peer pressure on the academic performance of students in Social Studies.

\section{Purpose of the Study}

The main purpose of the study is to investigate the influence of peer pressure on junior secondary school students' academic performance in Social Studies. Specifically, the study intends to:

- Assess the level of peer pressure among junior secondary school students of Social Studies in Mushin Local Government Area, Lagos State.

- Determine the difference between male and female secondary school students of Social Studies peer pressure influence on their academic performance in Mushin Local Government Area, Lagos State.

- Examine the difference across age groups peer pressure influence on academic performance of junior secondary school students in Social Studies in the study area. 


\section{Research Question}

What is the level of peer pressure influence on junior secondary school students of Social Studies in Mushin Local Government Area, Lagos State?

\section{HYPOTHESES}

Hypothesis 1: There is no significant difference between male and female students of Social Studies peer pressure influence on their academic performance in Mushin Local Government Area, Lagos State.

Hypothesis 2: There is no significant difference across age groups peer pressure influence on academic performance of junior secondary school students in Social Studies in the study area.

\section{Methodology}

A descriptive survey design was used. The purpose of using descriptive surveys was to collect detailed and factual information. Data was collected based on the concepts defined in the research model and hypotheses tested. The target population is all the junior secondary schools in Mushin Local Government Areas of Lagos State, Nigeria. Eight junior secondary schools were selected using simple random sampling technique. From each of the schools, thirty students were selected using simple random sampling technique. In all, we have 240 students that made up the sample for the study. Two self-designed research instruments were used for the study namely: Peer Pressure Questionnaire (PPQ) and Social Studies Test (SST). The PPQ consists of sections A and B. Section A measures the demographic characteristics of the respondents. This includes sex, religion, and age group. Section $B$ consists of items measuring peer pressure influence in students. Students are asked to respond to a 4 point rating scale ranging from Strongly Disagree (1) to Strongly Agree (4); with high scores indicating a positive or favorable response. Negative worded items were reversed and total score for the scale was generated. It consisted of 26 (twenty-six) items. The SST is an instrument for measuring students' academic performance. It consists 20 Multiple Choice Questions on Social Studies. Two marks were awarded each for correct answers giving a total of 40 (forty) marks. The highest score was 40 and the lowest score was 4.

In order to measure the extent to which the survey instrument has been able to achieve its aims, the process of content validity is employed by cross-examination and verification. Only items that are relevant and valid constitute the contents of the questionnaire. The validity of the instrument was ascertained by giving out to, experts in Social Studies and Test and Measurement, copies of the drafted questionnaires, research questions, hypothesis, alongside with the purposes of the study. The suggestions and recommendations of the experts were used for the final draft. The instruments were tested on 30 random junior secondary school students to ensure reliability. The data was analyzed using Cronbach's Alpha to determine the reliability of the instruments. Peer Pressure Questionnaire yielded a reliability coefficient of 0.80 while Social Studies Test (SST) yielded a reliability coefficient of 0.78 . It was then adjudged that the instruments were reliable for gathering the intended data.

Data collected were analyzed using frequencies, percentages and graphs as well as one-way multivariate analysis of variance (MANOVA). SPSS (Statistical Package for Social Sciences) computer software was used to run the analyses. The hypotheses were tested at 0.05 level of significance. At $5 \%$ level of significance, null hypotheses were rejected for tests with probability estimates lower than $5 \%(0.05)$ and conclude that they are statistically significant. Otherwise, we accept (when probability estimates are above 0.05 ) and conclude that there is no overall statistically significance.

\section{RESULTS}

The descriptive analysis of demographic data is presented in Tables 1 and 2 below.

Table-1: Distribution of Students by Gender

\begin{tabular}{|l|l|l|l|}
\hline \multicolumn{2}{|c|}{ Gender } & Frequency & Percent (\%) \\
\hline \multirow{3}{*}{} & Male & 110 & 45.8 \\
\cline { 2 - 4 } & Female & 130 & 54.2 \\
\cline { 2 - 4 } & Total & 240 & 100.0 \\
\hline
\end{tabular}

Table 1 show that $45.8 \%$ of the students were male, while $54.2 \%$ were female. Majority of the respondents were female students.

Table-2: Distribution of Students by Age group

\begin{tabular}{|l|l|l|l|}
\hline \multicolumn{2}{|c|}{ Age group } & Frequency & Percent (\%) \\
\hline \multirow{4}{*}{$11-13$} & 120 & 50.0 \\
\cline { 2 - 4 } & $14-16$ & 83 & 34.6 \\
\cline { 2 - 4 } & $17-$-above & 37 & 15.4 \\
\cline { 2 - 4 } & Total & $\mathbf{2 4 0}$ & 100.0 \\
\hline
\end{tabular}


Table 2 shows that $50 \%$ of the respondents were between age groups of $11-13$ years, $34.6 \%$ were between $14-16$ years and $15.4 \%$ were 17 years and above. Thus, majority of the respondents were between $11-13$ years age group with frequency of 120 students.

Research Question 1: What is the status of peer pressure influence on junior secondary school students?

To answer this question, students' responses to section $B$ of $P P Q$ were scored based on the items in the questionnaire as rated by the investigator. The individual respective scores were summed up to build their status of peer pressure influence. The mean and standard score of the group score were 50.61 and 20.84 respectively. Scores below the group mean score were considered as having a low peer pressure influence. Scores within the mean score and one standard deviation above the mean score (i.e. 50.61 71.45) were considered as moderate peer pressure influence while those with scores of 72 and above were considered as high peer pressure influence. The result is presented in table 1 below.

Table-4: Descriptive Statistics of peer pressure influence on junior secondary school students

\begin{tabular}{|l|l|l|l|}
\hline \multicolumn{2}{|l|}{ Status } & Frequency & Percent (\%) \\
\hline \multirow{4}{*}{} & Moderate & 148 & 61.7 \\
\cline { 2 - 4 } & Low & 42 & 17.5 \\
\cline { 2 - 4 } & High & 50 & 20.8 \\
\cline { 2 - 4 } & Total & 240 & 100.0 \\
\hline
\end{tabular}

Table 2 shows that $61.7 \%$ of the students had moderate peer pressure influence. Also, $17.5 \%$ of the students have low peer pressure influence while $20.8 \%$ of the students were found to have high peer pressure influence. There is an indication from this result that more than $50 \%$ of the students that participated in the study demonstrated moderate peer pressure influence.

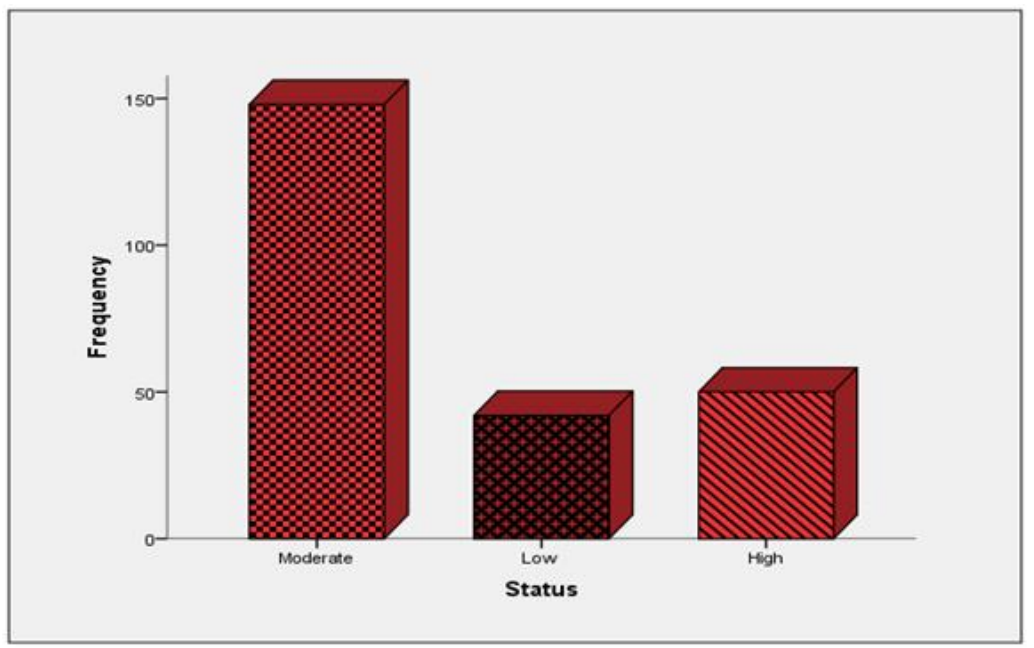

Fig-1: Bar-Chart of lower Primary school Pupils' performance in Social Studies

Figure 1 simply shows that "moderate" has the tallest bar indicating that senior secondary school students in Lagos State have moderate peer pressure influence.

Hypothesis 1: There is no significant difference between male and female students peer pressure influence on their academic performance

To test the hypothesis, data collected on were subjected to descriptive statistics and multivariate analysis of variance (MANOVA)

Table-5: Descriptive statistics of peer pressure influence on students' academic performance based on gender

\begin{tabular}{|l|l|l|l|l|}
\hline \multicolumn{2}{|l|}{ Gender } & Mean & Std. Deviation & N \\
\hline Peer Pressure Influence & Male & 48.61 & 21.718 & 110 \\
\cline { 2 - 5 } & Female & 52.30 & 19.998 & 130 \\
\cline { 2 - 5 } & Total & 50.61 & 20.842 & 240 \\
\hline Academic Performance & Male & 24.65 & 7.882 & 110 \\
\cline { 2 - 5 } & Female & 24.93 & 8.048 & 130 \\
\cline { 2 - 5 } & Total & 24.80 & 7.957 & 240 \\
\hline
\end{tabular}


Results in Table 5 shows the descriptive statistics of Peer pressure influence on students' academic performance based on Gender. It can be deduced from the table that peer pressure influence of male students have a mean score of $(\bar{x}=48.61)$ while peer pressure influence of female students have a mean score of $(\bar{x}=52.30)$. In the same vein, Academic performance of male students have a mean score of $(\bar{x}=24.65)$ whereas academic performance of female students have a mean score of $(\bar{x}=24.93)$. This implies that Female and Male students' peer pressure influence and academic performance are slightly different considering their close mean scores.

Table-6: Multivariate analysis of Variance (MANOVA) of Peer pressure influence on students' academic performance based on gender

\begin{tabular}{|l|l|l|l|l|l|l|l|}
\hline Effect & Value & F & Hypothesis df & Error df & Sig. & Partial Eta Squared \\
\hline \multirow{4}{*}{ Intercept } & Pillai's Trace & .935 & $1699.042^{\mathrm{b}}$ & 2.000 & 237.000 & .000 & .935 \\
\cline { 2 - 8 } & Wilks' Lambda & .065 & $1699.042^{\mathrm{b}}$ & 2.000 & 237.000 & .000 & .935 \\
\cline { 2 - 8 } & Hotelling's Trace & 14.338 & $1699.042^{\mathrm{b}}$ & 2.000 & 237.000 & .000 & .935 \\
& Roy's Largest Root & 14.338 & $1699.042^{\mathrm{b}}$ & 2.000 & 237.000 & .000 & .935 \\
\hline \multirow{5}{*}{ Gender } & Pillai's Trace & .008 & $.946^{\mathrm{b}}$ & 2.000 & 237.000 & .390 & .008 \\
\cline { 2 - 8 } & Wilks' Lambda & .992 & $.946^{\mathrm{b}}$ & 2.000 & 237.000 & .390 & .008 \\
\cline { 2 - 8 } & Hotelling's Trace & .008 & $.946^{\mathrm{b}}$ & 2.000 & 237.000 & .390 & .008 \\
\cline { 2 - 8 } & Roy's Largest Root & .008 & $.946^{\mathrm{b}}$ & 2.000 & 237.000 & .390 & .008 \\
\hline
\end{tabular}

Results in Table 6 reveal the multivariate analysis variance of peer pressure influence on students' academic performance based on gender. Two dependent variables were used: peer pressure and Academic performance. The independent variable was gender. Preliminary assumption testing was conducted to check for normality, linearity, univariate and multivariate outliers, homogeneity of variance, covariance matrices, and multicollinearity with no violations noted. Inferentially, it can be observed from the table that there was no statistically significant difference between male and females on the combined dependent variables, $F(2,237)=$ $0.97, p=.390 ;$ Wilks' Lambda= 0.99; partial eta squared $=.008$.

Hypothesis 2: There is no significant difference across different age groups peer pressure influence on academic performance.

To test the hypothesis, data were subjected to descriptive statistics and multivariate analysis of variance (MANOVA)

Table-7: Descriptive statistics of peer pressure influence on students' academic performance based on age group

\begin{tabular}{|c|c|c|c|c|}
\hline & Age group & Mean & Std. Deviation & $\mathbf{N}$ \\
\hline \multirow[t]{4}{*}{ Peer Pressure } & $11-13$ & 49.08 & 20.696 & 120 \\
\hline & $14-16$ & 51.39 & 20.896 & 83 \\
\hline & 17-above & 53.81 & 21.299 & 37 \\
\hline & Total & 50.61 & 20.842 & 240 \\
\hline \multirow[t]{4}{*}{ Academic performance } & $11-13$ & 24.58 & 8.453 & 120 \\
\hline & $14-16$ & 25.45 & 7.911 & 83 \\
\hline & 17-above & 24.05 & 6.316 & 37 \\
\hline & Total & 24.80 & 7.957 & 240 \\
\hline
\end{tabular}

Results in Table 7 shows the descriptive statistics of Peer pressure influence on students' academic performance based on age groups. It can be deduced from the table that peer pressure influence of students whose age group is $11-13$ have a mean score of $(\bar{x}=49.08)$ while peer pressure influence of students whose age group is $14-16$ have a mean score of $(\bar{x}=51.39)$ and peer pressure influence of students whose age group is 17-above have a mean score of $(\bar{x}=53.81)$. In the same vein, Academic performance of students whose age group is $11-13$ have a mean score of $(\bar{x}=24.58)$ while academic performance of students whose age group is 1416 have a mean score of $(\bar{x}=25.45)$ and academic performance of students whose age group is 17 and above have a mean score of $(\bar{x}=24.05)$. This implies that peer pressure influence and academic performance of students based on age group are slightly different considering their close mean scores. 
Table-8: Multivariate analysis of Variance (MANOVA) of Peer pressure influence on students' academic performance based on age group

\begin{tabular}{|c|c|c|c|c|c|c|c|}
\hline \multicolumn{2}{|l|}{ Effect } & Value & $\mathbf{F}$ & Hypothesis df & Error df & Sig. & Partial Eta Squared \\
\hline \multirow[t]{4}{*}{ Intercept } & Pillai's Trace & .920 & $1360.786^{b}$ & 2.000 & 236.000 & .000 & .920 \\
\hline & Wilks' Lambda & .080 & $1360.786^{b}$ & 2.000 & 236.000 & .000 & .920 \\
\hline & Hotelling's Trace & 11.532 & $1360.786^{b}$ & 2.000 & 236.000 & .000 & .920 \\
\hline & Roy's Largest Root & 11.532 & $1360.786^{b}$ & 2.000 & 236.000 & .000 & .920 \\
\hline \multirow[t]{4}{*}{ Agegroup } & Pillai's Trace & .011 & .653 & 4.000 & 474.000 & .625 & .005 \\
\hline & Wilks' Lambda & .989 & $.651^{\mathrm{b}}$ & 4.000 & 472.000 & .627 & .005 \\
\hline & Hotelling's Trace & .011 & .648 & 4.000 & 470.000 & .628 & .005 \\
\hline & Roy's Largest Root & .007 & $.841^{c}$ & 2.000 & 237.000 & .433 & .007 \\
\hline \multicolumn{8}{|c|}{ a. Design: Intercept + Agegroup } \\
\hline \multicolumn{8}{|c|}{ b. Exact statistic } \\
\hline \multicolumn{8}{|c|}{ c. The statistic is an upper bound on $\mathrm{F}$ that yields a lower bound on the significance level. } \\
\hline
\end{tabular}

Results in Table 8 reveal the multivariate analysis variance of peer pressure influence on students' academic performance based on age group. Two dependent variables were used: peer pressure and Academic performance. The independent variable was age group. Preliminary assumption testing was conducted to check for normality, linearity, univariate and multivariate outliers, homogeneity of variance, covariance matrices, and multicollinearity with no violations noted. Inferentially, it can be observed from the table that there was no statistically significant difference between different age groups on the combined dependent variables, $F$ $(2,236)=0.65, p=.627 ;$ Wilks' Lambda $=0.99 ;$ partial eta squared $=.005$.

\section{DIsCUSSION OF FINDINGS}

Findings of the study showed that the study sample demonstrated moderate peer pressure influence on junior secondary school students of Social Studies. The result corroborates the findings of Bobbies \& Elhaney [14] indicating that peer pressure refers to the way the people of the same social group act or believe in order to influence one another, often in negative ways. Peer pressure is something everybody has to deal with at some time in one's life. Peer pressure is defined as when people of one's age encourages or urges him to do something or to keep off from doing something else, irrespective of the person's desire to or not to [15, 16]. Peer pressure is emotional or mental force from people belonging to the same social group (such as same age grade or status) to act or behave in a manner similar to themselves. Peer pressure has a great influence on adolescent behavior and reflects young people's desire to fit in and be accepted by others [10]. Peer pressure is also known as peer influence, and it involves changing one's behavior to meet the perceived expectation of others [18].

The results of the study further indicated that there was no statistically significant difference between male and females junior secondary school students of Social Studies peer pressure influence on their academic performance. The result upheld the findings of Ikwuji [18] who conducted a study on influence of age, gender, and value orientation on adolescent students' moral judgments in conflict situations. The researcher found out that majority of the adolescents based their moral judgment in conflict situations on peer - approved value shows that the peer - group has enormous influence on how the adolescents think and act. The researcher also found that there was no gender difference between adolescent male and female in their moral judgments in conflict situations. This shows that in organizing a moral instruction class the teacher should make it a point of duty to see that both sexes mix freely so that they could share moral experiences in discussing conflicting moral problems. Hence, parents, teachers and other significant adults should avoid unhealthy behaviour that can easily be imitated by adolescent students such as drunkenness, telling lies, skipping schools, cultism and smoking relate. Relating the study to the present study, students should be imitators of good behaviour.

The results of the study finally revealed that there was no statistically significant difference between different age groups on the combined dependent variables in the study area. The result also buttressed the account of lkwuji $[18,19]$ that that there was no significant difference in age groups of learners and that socio-economic status of parents of the learners have significant influence on peer pressure thus influencing the learners' academic performance in schools.

\section{CONCLUSION}

Based on the findings of the study, it can therefore be concluded that the level of peer pressure among junior secondary school students is moderate and that the peer pressure influenced their academic performance though moderating variables were not significantly have influence on the students' performance in Social Studies in the study area.

\section{RECOMMENDATIONS}

The following recommendations are put forward based on the findings of this study

- Federal and State Government, Local Government, Ministry of Education and policy makers should come up with policies to

(c) South Asian Research Publication, Bangladesh Journal Homepage: www.sarpublication.com/sarihss 
ensure that peer pressure is checked in secondary schools.

- $\quad$ Parents and guidance should be watchful of the types of friends kept by their wards.

- The parent-child relationship should be cordial enough to permit adolescents to discuss their issues with their parents.

- School counsellors should also provide usable and adequate information both to the students and their parents about forms of peer pressure in public secondary schools.

- Conferences, seminars and workshops should be organized for teachers, students, parents and guidance to reduce peer pressure in the society at large.

\section{REFERENCES}

1. Allen, J. P., Porter, M. R., McFarland, F. C., Marsh, P., \& McElhaney, K. B. (2005). The two faces of adolescents' success with peers: Adolescent popularity, social adaptation, and deviant behavior. Child development, 76(3), 747-760.

2. Hardcastle, M. (2002). Beating peer pressure: Your guide to teen advice. California: Advice Book.

3. Silverman, W. K., \& Ollendick, T. H. (1999). Developmental issues in the clinical treatment of children. Allyn \& Bacon.

4. Carver, K., Joyner, K., \& Udry, J. R. (2003). National estimates of adolescent romantic relationships. In Adolescent romantic relations and sexual behavior (pp. 37-70). Psychology Press.

5. Santrock, J. W. (2007). Adolescent Attachment, peer relationships, and school success. Life-span development. (11th ed.) New York: McGraw-Hill.

6. Temitope, B. E., \& Christy, O. F. (2015). Influence of peer group on academic performance of secondary school students in Ekiti State. Int. J. Innov. Res. Develop. 4(1):324-331.

7. Jones, V. (2010). Stronger links: A guide to good practice for children's familybased short-term care service. Briston: Policy Press.

8. Hartney, E. (2011). What is peer pleasure? http://www.agrange.edu/responses/pdf/citations/nursing/adolscents $\% 20$ selfesteem. pdf update July 5, 2011.

9. Weinfield, L. (1991). Remembering the 3rd wave. Retrieved March, 6, 2010.

10. Arief, G. I. \& Martin, A. J. (2011). Peer relationship and adolescents' academic and non-academic outcomes: some-sex and opposite-sex and opposite-sex peer effect and the role of school engagement. British Journal of Educational Psychology, 81, 183-206.

11. Scortt. (2012). http://www.ehow.com/about_6398585_meaning-academic.

12. Annie, W., Howard, W. S., \& Mildred, M. W. (2006). Achievement and ability tests-definition of the domain, educational measurement.

13. Aremu, A. O., \& Sokan, B. O. (2003). A multi-causal evaluation of academic performance of Nigerian learners: Issues and implications for national development. Department of Guidance and counseling, University of Ibadan.

14. Allen, J. P., Porter, M. R., McFarland, F. C., Marsh, P., \& McElhaney, K. B. (2005). The two faces of adolescents' success with peers: Adolescent popularity, social adaptation, and deviant behavior. Child development, 76(3), 747-760.

15. Ryan, A. M. (2000). Peer groups as a context for the socialization of adolescents' motivation, engagement, and achievement in school. Educational Psychologist, 35(2), 101-111.

16. Uche, V. O. (2010). The effects of family structure, socio-economic and parents' hood on the academic performance of Nigerian university students, Edo: Kamla Raj Publishers.

17. Barnes, G. M., Welte, J. W., Hoffman, J. H., \& Dintcheff, B. A. (2005). Shared predictors of youthful gambling, substance use, and delinquency. Psychology of Addictive Behaviors, 19(2), 165.

18. Ikwuji. (2005). A study on influence of ages, gender and value orientation on adolescent students moral judgment in conflict situations. Unpublished M.Ed Thesis University of Nigeria, Nsukka.

19. Hartney, H. (1990). Make time to manage your time more effectively. Executive Educator. 